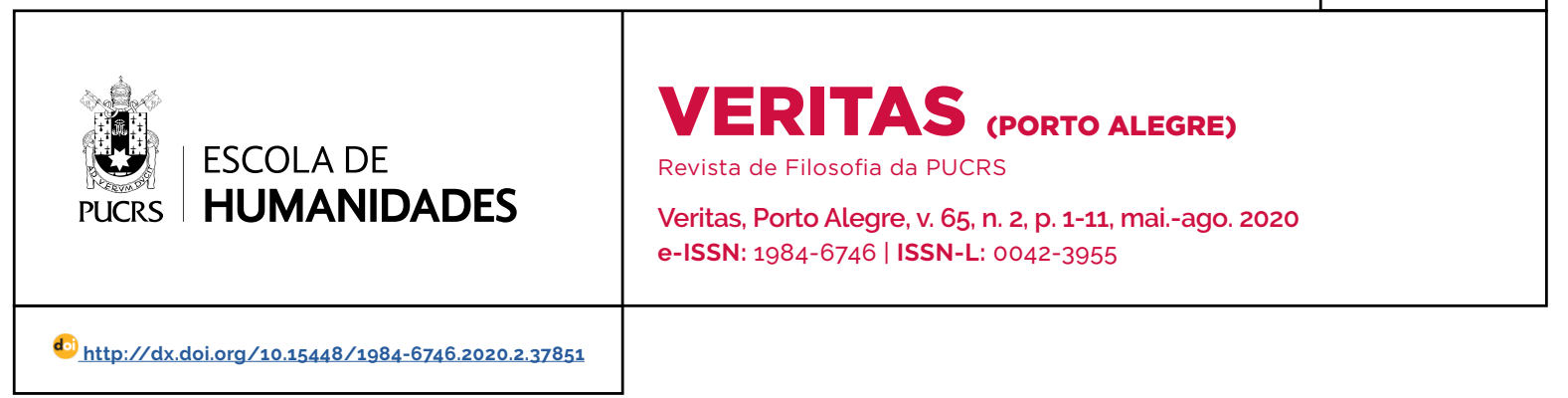

SEÇÃO: ESTÉTICA

\title{
Memória, ética e estética: algumas considerações a partir de Adorno, Levinas e Gur-Ze'ev
}

\author{
Memory, ethics \& aesthetics: some considerations from Adorno, Levinas and Gur-Ze'ev \\ Memória, ética y estética: algunas consideraciones desde Adorno, Levinas y Gur-Ze'ev
}

\section{Bruno Antonio Picoli ${ }^{1}$ \\ orcid.org/0000-0001-6831-2199 \\ bruno.picoli@uffs.edu.br}

\section{Alexandre Anselmo \\ Guilherme $^{2}$}

orcid.org/0000-0003-4578-1894

alexandre.guilherme@pucrs.br

Recebido em: 28 abr. 2020. Aprovado em: 9 mai. 2020. Publicado em: 28 jul. 2020
Resumo: A reflexão parte da tarefa que Benjamin atribui aos que estão vivos: originar um verdadeiro "estado de exceção". Compreende-se que essa é a tarefa primeira de uma Educação Histórica ética e estética. O artigo está organizado em três partes que compreendem os três elementos indissociáveis que constituem os primeiros movimentos no sentido de superar o "estado de Exceção" da violência sem memória. Na primeira parte, discutimos, a partir de Adorno, o "estado de exceção" da violência sem memória e reafirmamos o dever de memória que se opõe a barbárie. Na segunda parte, comentamos, seguindo Levinas, a ética da responsabilidade. Na terceira, analisamos a estética do Eros contraeducativo de Gur-Ze'ev. Conclui-se que a postura de um pensar histórico ético e estético perpassa a recusa de esquecer e o desenvolvimento de uma atitude crítica para consigo mesmo, para com o Outro, e finalmente para com a realidade.

Palavras-chave: História. Memória. Ética. Estética. Eros.

Abstract: The reflection starts from the Benjamin's task to those who are alive: to create a real "state of exception". It is understood that this is the primary task of an ethical and aesthetic Historical Education. The article is organized in three parts that understand the three inseparable elements that constitute the first movements towards overcoming the "state of Exception" of violence without memory. In the first part, it discusses, from Adorno, the "state of exception" of violence without memory and reaffirm the duty of memory that opposes barbarism. In the second part, it comments, following Levinas, on the ethics of responsibility. In the third, it analyses the aesthetics of the Gur-Ze'ev's counter-educational Eros. It concludes that the posture of an ethical and aesthetic historical thinking goes through the refusal to forget and the development of a critical attitude towards oneself, towards the Other, and finally towards reality.

Keywords: History. Memory. Ethics. Aesthetics. Eros.

Resumen: La reflexión comienza desde la tarea de Benjamin hacia aquellos que están vivos: crear un verdadero "estado de excepción". Se entiende que esta es la tarea principal de una Educación Histórica ética y estética. El artículo está organizado en tres partes que comprenden los tres elementos inseparables que constituyen los primeros movimientos para superar el "estado de excepción" de la violencia sin memoria. En la primera parte, discute, desde Adorno, el "estado de excepción" de la violencia sin memoria y reafirma el deber de memoria que se opone a la barbarie. En la segunda parte, comenta, siguiendo a Levinas, sobre la ética de la responsabilidad. En el tercero, analiza la estética del Eros contraeducativo del Gur-Ze'ev. Concluye que la postura de un pensamiento histórico ético y estético pasa por la negativa a olvidar y el desarrollo de una actitud crítica hacia uno mismo, hacia el Otro y finalmente hacia la realidad.

Palabras clave: Historia. Memoria. Ética, Estética. Eros. 
"Até o minimo gesto, simples na aparência,

Olhem desconfiados! Perguntem Se é necessário, a começar do mais comum!

E, por favor, não achem natural

O que acontece e torna a acontecer Não se deve achar que nada é natural!

Numa época de confusão e sangue, Desordem ordenada, arbitrio de propósito, Humanidade desumanizada Para que imutável não se considere Nada".

(Bertold Brecht)

\section{Introdução}

A peça de Brecht, $A$ exceção e a regra, escrita entre 1929 e 1930, reverberou no pensamento de um de seus mais próximos amigos, Walter Benjamin. Menos de uma década depois, Benjamin compõe suas teses sobre o conceito da História e, na de número oito, denuncia como a desumanização é a regra e, que mesmo os que a ela se opõe fazem por caminhos repletos de armadilhas e enganos, não vivenciando o assombro filosófico que só outra forma de experimentar o tempo, a história, pode oferecer (1994, p. 226). Benjamin (2011, p. 153-154), também, nos anuncia a tarefa que cabe aos que estão vivos e ainda não desistiram de viver uma vida plena, afirmando que: "É falsa e vil a proposição de que a existência teria um valor mais alto do que a existência justa, quando existência significar nada mais do que a mera vida". Na luta contra a barbárie, nossa tarefa é originar um verdadeiro "estado de exceção", em que vida não seja mera vida, em que o Outro não seja abandonado, em que a justiça constitua a base fundacional da realidade.

Nos propomos aqui a enfrentar o desafio de Benjamin: a tarefa de construir um verdadeiro "estado de exceção", ou, pelo, menos, indicar alguns dos possiveis primeiros passos. Compreendemos que essa é a tarefa primeira hoje de uma Educação Histórica que se recusa a oferecer mais irrelevâncias e distrações que obnubilam a razão pelo excesso de luz entorpecedora, criando condições para a antimemória, para que esqueçamos o que na verdade não podemos esquecer. Concordamos com Souza (2006, p. 136) que esse movimento se inicia com a conjunção de três elementos "dispersos em meio aos estilhaços do presente", provenientes, portanto, de diferentes perspectivas e autores: a memória do real, a ética e a estética. A reflexão está, portanto, organizada de forma que atenda esses três elementos que, na vida, no mundo, são indissociáveis entre si. $\mathrm{Na}$ primeira parte, discutimos, a partir de Adorno, o "estado de exceção" da violência sem memória e reafirmamos o dever de memória que se opõe a barbárie. Na segunda parte, comentamos, seguindo Levinas, a ética da responsabilidade. $\mathrm{Na}$ terceira, analisamos a estética do Eros contraeducativo de Gur-Ze'ev.

\section{O Estado de Exceção como regra geral da violência sem memória}

O assombro denunciado por Benjamin em sua oitava tese sobre o conceito da História não é um assombro meramente teórico que não reflete a realidade (SOUZA, 2006, p. 131); de fato, é um assombro de cunho filosófico porque trata do descompasso entre o formal, as questões e respostas oferecidas pelo pensamento pós-iluminista, e o real, o concreto. ${ }^{3}$ Trata-se, portanto, do assombro de uma razão entorpecida que, embora honesta e profundamente preocupada com a questão humana, seu futuro e sua possibilidade, não consegue superar a condição do Anjo da História da nona tese de Benjamin (1994, p. 226): só vê crescer a pilha de mortos e ruinas que, disposta sob seus pés, cresce até $o$ céu. Como o próprio filósofo denuncia, na oitava tese, o estado de exceção se perpetua porque aqueles que a ele se opõe o fazem "em nome do progresso, considerado com uma norma histórica" (BENJAMIN, 1994, p. 226). A noção de progresso agregada a da História, favorecendo a manutenção do "estado de exceção" porque "toda a História" pôde ser concebida com um

3 Toda reflexão filosófica deve ter uma forte conexão para com a realidade, ser "ancorada" no mundo - apenas assim é válida. Reflexões filosóficas em que faltam essa ligação com o mundo são meros exercícios mentais, tendo pouca ou nenhuma validade, sendo dificeis de compreensão. 
processo de crescente avanço, e que "apesar das recaídas [...] O futuro será diferente do passado, vale dizer, melhor" (KOSELLECK, 2006, p. 317318). Esse entorpecimento da razão, ainda em Benjamin, oferece como único conhecimento filosoficamente válido o de que tal concepção da História é insustentável. Entretanto, é necessário que libertemos a razão de sua torpeza para percebermos essa insustentabilidade.

A razão entorpecida procura o prazer imediato (SOUZA, 2006, p. 134; GUR-ZE'EV, 2002) e, incapaz de experienciar uma crise de sentido é, concomitantemente, incapaz de sair dela. Habita um limbo de prazeres renovados em que o individuo é, ao mesmo tempo, engolido e satisfeito pelo sistema que o engole (ADORNO; HORKHEIMER, 1985, p. 15), a vítima entusiasta de sua aniquilação enquanto ser humano (GUR-ZE'EV, 2005b, p. 170). Tal é a condição humana na contemporaneidade alardeada como um estágio superior de nossa civilização pelos profetas da tecnologia, do "encontro sem face-a-face". Santaella (2013, p. 179) afirma que a ubiquidade oferece um sentimento de onipresença, e que é a própria ubiquidade a condição humana que marca o nosso tempo. Ao estar o tempo todo em todos os lugares não se está em lugar nenhum em tempo algum. Há um excesso de presença em que a própria possibilidade de presente é sequestrada, e se evanesce. Em tal condição, conforme Souza (2006, p. 134).

a memória é continuamente esvaziada, para dar lugar a mais quinquilharias produzidas em série pela agilidade das racionalidades imagéticas que se sucedem sem fim. Repleto de tudo, o presente encontra-se, na verdade vazio, pois a multiplicação do irrelevante que toma o lugar do notável tomou para si exatamente essa função: [...] o que é verdadeiramente decisivo - em todos os sentidos - fica recalcado pelo excesso de resíduos físicos e mentais que sobraram do momento que já desapareceu. É nesse sentido que o mundo contemporâneo é o mundo da anti-memória.

Estamos em situação tal que o nosso tempo pode ser considerado o tempo de Funes e do antiFunes, concomitantemente, em uma alusão a obra e nos sentidos que lhe atribuem o autor, Jorge Luis Borges (1974). Souza (2006, p. 134) interpreta afirmando que é o tempo de Funes porque tudo é lembrado e é o tempo do antiFunes porque tudo é esquecido, até aquilo que deveria ser inesquecivel. $\mathrm{O}$ excesso de dados, colocados um ao lado do outro, ou um depois do outro, sem axiologia, poluem o pensamento, entorpecem a razão. Somos assim, incapazes de lembrar o que não podemos esquecer, porque tudo "é hoje atirado à vala comum da superprodução de dados midiáticos". A comunicação é obstruída pelo ruido parasitário (SERRES, 2007, p. 3: GUILHERME, 2015. p. 5). Os profetas da ubiquidade favorecida pelas tecnologias de comunicação e informação não podem afirmar inadvertência. Benjamin, no início do século 20, já asseverava a perda do sentido do sagrado promovida pela reprodutibilidade técnica: para ele, o incremento da reprodutibilidade técnica, o avanço das tecnologias, implicava o fim da autenticidade e a consequência disso era que a distração (o ruido, o parasita) tornar-se-ia o modo dominante do comportamento social (KYONG-MIN, 2013, p. 617). Já no final do século 20, Michel Serres (2007), na sua obra Le Parasite, também comentaria perspicazmente sobre a distração, o parasita, nas comunicações humanas - quer dizer na falta de comunicação. Serres afirma que essa distração, o parasita, procurar gerar problemas e dominar nossas relações de modo que conflitos são gerados continuamente entre indivíduos. Assim, nos limites da racionalidade instrumental, ubíqua e pervasiva, não há espaço para o amor, para a transcendência, "mas há muito espaço para manipular o amor e a necessidade de transcendência sob bandeiras muito diferentes, como 'amor à pátria' ou 'a voz de Deus'" (GUR-ZE'EV, 2005b, p. 162).

O aparente paradoxo de um tempo que é, ao mesmo tempo, o de Funes e o do antiFunes, é resolvido pela leitura que Souza (2008a, p. 36) faz da sala de espelhos de Rosenzweig e que Agamben (2009, p. 59) faz da Segunda Consideração Extemporânea de Nietzsche. Para o filósofo italiano, o que caracteriza o nosso tempo é o excesso de luz. Essa iluminação antes de esclarecer, de fato cega e entorpece a razão. Superar o entorpecimento é, então, perceber o que as luzes ofuscam, aquilo que é sombra. Para o filósofo brasileiro, nessa sala 
superiluminada, só é possível ver a si mesmo. 0 individuo, nessa sala, se vê preso em suas projeções e limites. Está cego para o Outro. Assim, a tarefa de criar o verdadeiro estado de exceção consiste em quebrar os espelhos, se libertar da iluminação perfeita da sala, sair do centro do mundo, procurar o encontro com o Outro. Souza (2004, p. 123-124, grifo do autor) explicita isso na seguinte passagem:

Tais fantasmas, reflexos luminosos de um poder meramente virtual, dirigem-se a tudo e a nada, menos ao que interessa: ao real e, indiretamente, a si mesmos. São incapazes, no jogo de espelhos que criaram e com o qual se comprazem, de ver algo além de si mesmos e de seus reflexos; a ilusão de uma sala de espelhos é aqui reproduzida, mas com o perverso diferencial de pretensa credibilidade filosófica. Mas pensar é quebrar espelhos, com o risco, e mesmo a certeza, do ferimento e da decepção que o opaco substrato dos espelhos reserva a quem os quebra.

No "estado de exceção" da violência sem memória, há apenas espaço para o Mesmo, o similar; O Outro é rejeitado e abandonado. O Outro está exposto ao risco que é viver em um Estado de Exceção em que direito e vida se confundem (AGAMBEN, 2002), mas em que a vida está totalmente banalizada (SOUZA, 2006, p. 135). O Outro está integrado como conceito e excluido como pessoa. Um conceito não tem direitos, e a ele tudo pode acontecer: "não há necessidade do surgimento do totalitarismo para dar-nos conta de que vivemos em um mundo de pernas para o ar" (ARENDT, 1995, p. 36). A condição de abandono do Outro é fruto do que Adorno (1995, p. 129) identifica, em nivel individual, como consciência coisificada, caracterizada por uma incapacidade, ou mesmo uma recusa, nem sempre consciente, de fazer experiências, de dialogar, de romper, portanto, a sala de espelhos. O individuo refugia-se no interior da sala, onde se sente seguro, já que tudo que vê é mais do Mesmo, que é ele próprio, suas projeções, seus similares. "Esse tipo encontra-se, entrementes [...] muito mais disseminado do que se poderia imaginar" (ADORNO, 1995, p. 129). Para Adorno, o traço mais característico dessa consciência coisificada, que vê a si e aos Outros como coisas, não como pessoas, é a incapacidade de se relacionar, de comunicar, de amar. Não necessariamente do amor em sentido sentimental, "mas denotando a carente relação libidinal com outras pessoas" (ADORNO, 1995, p. 133). Ou seja, são frias, não desejam estar com outras pessoas que não iguais a elas próprias e "A capacidade de amar, que de alguma maneira sobrevive, eles precisam aplicá-la aos meios [...] Seu amor era absorvido por coisas, máquinas enquanto tais" (ADORNO, 1995, p. 133).

Essa relação com a História, essa antimemória, em termos de Souza (2006), não é fruto do acaso, nem provém de geração espontânea, é alimentada e retroalimentada por uma educação que favorece o esquecimento do que importa, que produz e é produzida pela incapacidade de realizar experiências humanas e "pela incapacidade de sentir intensamente a realidade do particular" (2006, p. 134). Uma educação que promove aquilo que Brecht nos pede para evitar: a naturalização do absurdo, a violência que abandona o Outro à própria sorte, que não assume a responsabilidade ética do chamado do Outro, que faz com que nós, ao abandonarmos o Outro e sem oferecer resistência à barbárie que o mata, tornamo-nos, também, assassinos de nós mesmos (ADORNO, 1995, p. 137). A essa forma de educação, chamamos, seguindo Gur-Ze'ev (2005a, 2005b, 2007, 2010b, 2010c), Educação Normalizante. Em Gur-Ze'ev (2005b, p. 165):

\begin{abstract}
A educação normalizante deve integrar um aparato conceitual específico em um conjunto especifico de valores. [...] O véu do Ser é tecido a cada novo momento. [...]. A evidência, não apenas nos horizontes da razão crítica, da coexistência morna e do distanciamento da natureza, encobre a possibilidade de enfrentar a violência, que estabelece conceitos especificos como relevantes, verdadeiros ou possiveis e outros como não. [...]. A educação normalizante só é possivel porque resultado de seu enorme sucesso criativo.
\end{abstract}

Criativa, ela se manifesta com diversas faces. Em todas elas o ardil da anistia e da desresponsabilização, do perdão do imperdoável, do esquecimento do inesquecivel, daquilo que não podemos esquecer por ser grandioso e daquilo que não devemos esquecer por ser horrivel. Nas tramas da educação normalizada, 
nesse deserto mental cuidadosamente criado e alimentado, que acontece o fundamental para que o estado de exceção em que vivemos se perpetue [...] Todo o vital escorre e é devorado por esse solo devastado: o tempo, a memória, os tecidos que um dia significaram algo. Uma forma inusitada de violência se instaura (SOUZA, 2006, p. 135, grifo do autor).

O estado de exceção da violência sem memória, da antimemória, coloca diante de nós o perigo de reincidirmos nas mais perversas experiências desumanizantes, uma vez, que, como lembra Adorno, ainda não superamos a catástrofe, ainda precisamos empreender um grande esforço de desbarbarização (ADORNO, 1995, p. 119, 155).

Paradoxalmente, nesse esforço precisamos enfrentar as forças do próprio processo civilizacional, de nossa tradição política e de pensamento, já que, juntamente com a civilização, a tradição carrega consigo a anticivilização; quer dizer, o processo civilizatório da humanidade está carregado de elementos desumanizantes (ADORNO, 1995, p. 133). Precisamos enfrentar a questão da corrosão civilizacional, que amplifica a fúria contra o mundo como o lugar para se compartilhar com o Outro sem absorvê-lo e sem ser absorvido por ele. Assim, se voltar para o problema da barbárie é, portanto, encarar a nossa civilização, sua educação e sua relação com o tempo, com a história, não só no sentido de "como isso foi possivel", mas, sobretudo, na indagação da possibilidade de reingresso na barbárie que, como Adorno em seu típico pessimismo, ou talvez realismo, enfatiza, "continuará existindo enquanto persistirem no que têm de fundamental as condições que geram esta regressão. É isto que apavora" (ADORNO, 1995, p. 119). É preciso encarar nosso tempo para além da razão entorpecida. É preciso mergulhar na crise com o objetivo de transformá-la.

Essa crise é experienciada por todos que percebem o descompasso entre o formal e o real, por aqueles que não se refugiam, por ingenuidade ou hipocrisia, em um ou outro sistema filosófico que desaba quando entra em cena o fator humano, imprevisivel e impossivel de conceituação. Essa crise não emerge pela mera atividade contemplativa e nem de forma suave, de fato é muito mais fácil recorrer aos sistemas filosóficos totalizantes. Essa crise toma a forma de um obstáculo, de um trauma, que coloca em xeque o sentido da História e a relação com o que não é o Mesmo, com o que é Outro (SOUZA, 2008b, p. 56; 2010, p. 117). Concordamos com Souza (2006), quando afirma que o enfrentamento, sério, responsável, comprometido não com uma escola de pensamento, com um autor, mas com o real concreto a partir dos recursos que temos em mãos, provenientes das mais variadas mãos, começa

pela conjunção desses três elementos [...]: a memória do real, revivido pelo instante presente onde o concreto assume a sua verdadeira forma; a ética, consequência da reconsideração radical do sentido humano enquanto agir e se construir subjetivamente pelo encontro com a Alteridade; e a estética, antídoto sereno da violência totalitária (SOUZA, 2006, p. 135).

Trata-se de elementos separados e entrelaçados, de tal modo que um é impossivel sem o outro, um não faz sentido sem o outro.

\section{O verdadeiro estado de exceção da ética da responsabilidade: a violência do rosto}

Afirma Adorno (1995, p. 134) que se as pessoas não fossem frias em relação umas às outras, ao que acontece com os Outros, salvo com aquela pequena porção de pessoas com quem se mantém vínculos estreitos, a barbárie, da qual Auschwitz é a manifestação mais brutal, "não teria sido possivel, as pessoas não o teriam aceitado". A afirmação de Adorno implica que a superação da barbárie, do "estado de exceção" como regra geral, exige uma ética da responsabilidade pelo Outro. Identificamos em Levinas a fundamentação dessa ética: "A responsabilidade para com Outrem - anterior a minha liberdade - anterior em relação ao presente e à representação - é passividade mais passiva que toda a passividade" (LEVINAS, 1978, p. 31). De fato, e em consonância com as noções éticas de Adorno e sua crítica da barbárie, Levinas que durante os anos pré-Segunda Guerra Mundial, se interessava por questões filosóficas conectadas a metafísica, particularmente a existência, no pós-Segunda Guerra Mundial, se volta para a ética, em grande parte por suas experiências como oficial 
aprisionado nem um campo durante a guerra e a perda de toda a sua familia Lituana em campos de extermínio Nazistas (GUILHERME; MORGAN, 2019, p. 117). É importante lembrar que Levinas não está primariamente preocupado em desenvolver um sistema ético, mas em estabelecer o significado da ética. Levinas (2009, p. 90) diz: "Minha tarefa não consiste em construir a ética; eu apenas tento encontrar seu significado".

Assim, a relação ética de responsabilidade pelo Outro implica sujeição ao Outro, mas não sujeição ao poder do Outro. Significa que Eu sou responsável pelo Outro, respondo ao seu chamado. Já a forma como respondo ao seu chamado é posterior, mesmo a recusa em atender não significa que não sou responsável por ele. Recusar em assumir a responsabilidade não é equivalente de negar a responsabilidade, a ela sou obrigado, isso está fora do Mesmo, lhe é externa. O Mesmo, nessa relação ética, é responsável por uma responsabilidade que se origina no Outro, no seu chamado, não no Mesmo. Conforme Levinas (1989, p. 196): "A vontade é livre de assumir a responsabilidade no sentido que quiser, mas não tem a liberdade de rejeitar essa mesma responsabilidade, de ignorar o mundo palpável em que o rosto de Outrem a introduziu". É na ética da responsabilidade pelo Outro que o Outro e Eu somos, não como Totalidade, mesmidade, nem mesmo como dialética, em que o Outro é antítese do Mesmo, de cujo "encontro" emerge a sintese (isso é só outra maneira de aniquilação do Outro, de coisificação do Outro, uma outra forma, refinada evidentemente, de manifestação da consciência coisificada). A ética da responsabilidade exige separação absoluta e transcendente, na qual o Mesmo e o Outro, mesmo em relação, continuam sendo o Mesmo e o Outro, transcendendo de suas condições iniciais sem se fundirem, mantendo-se separados (LEVINAS, 1989, p. 24, 89).

Sobre a impossibilidade de negar a responsabilidade, Levinas (1997, p. 194) afirma:

A morte do Outro homem me concerne e me questiona como se eu me tornasse, por minha eventual indiferença, o cúmplice desta morte invisivel ao Outro que ai se expõe; e como se, antes de ser eu mesmo votado a ele, tivesse que responder por esta morte do Outro e não deixar outrem só, em sua solidão mortal. É precisamente neste chamamento de minha responsabilidade pelo rosto que me convoca, me suplica e me reclama, é neste questionamento que outrem é próximo.

A afirmação de Levinas se aproxima demasiadamente do tipo de culpa que Jaspers (2018, p. 24. grifo do autor) chama "metafísica":

Existe uma solidariedade entre pessoas enquanto pessoas, que torna cada um corresponsável por toda incorreção e toda injustiça no mundo [...] Se não dediquei minha vida a evitar o assassinato de outros, mas fiquei ali, sinto-me culpado de certa forma que não é compreensível do ponto de vista jurídico, político e moral. O fato de eu ainda estar vivo ao acontecer certa coisa deita-se sobre mim como uma culpa inextinguivel.

Assim, mesmo em situações terriveis, como é a nossa condição no "estado de exceção da violência sem memória", da naturalização do absurdo e da normatização e mecanicização das relações entre seres humanos, da racionalidade instrumental, ainda somos responsáveis uns pelos outros. Mesmo nas mais terriveis experiências históricas, a indiferença ainda é uma forma de responder ao chamado ético da responsabilidade, não uma ação tomada pela falta de opções, que esconde, por sua vez, uma retórica de desresponsabilização. Ademais, a noção de responsabilidade ética, em Levinas, é assimétrica e não exige reciprocidade como condição de sua manifestação: "a subjetividade humana como ser-para, como um-para-outro, a responsabilidade como transcendência para com o outro, anterior a qualquer engajamento da liberdade" (PIVATTO, 2011, p. 225). Guilherme e Morgan (2019, p. 123) explicam essa noção:

\begin{abstract}
A assimetria entre o um e o Outro é crucial para Levinas, mas não deve ser entendida como uma hierarquia das relações humanas. A assimetria é, na verdade, bilateral, porque o um é também o Outro do Outro. Portanto, do mesmo modo, quando o rosto do Outro me insta a responder, meu próprio rosto também insta o Outro a fazer o mesmo.
\end{abstract}

Isso significa ser-para-Outro na transcendência que rompe com a razão entorpecida de si Mesmo 
da Totalidade. Conforme Pivatto (2011, p. 224), em Levinas, "a responsabilidade constitui o humano no homem, constitui a subjetividade como relação ao Outro - relação de alteridade - e não como relação de identidade em que o eu se refere a si mesmo". Sou responsável pelo Outro mesmo antes de tomar consciência dessa responsabilidade. É o fato de Eu ser humano o que me faz responsável, não o fato de ser consciente ou engajado.

No princípio da separação da relação ética da alteridade, da relação entre o Mesmo e o Outro, o outro não pode ser objetivado, conceituado, e, incorporado pelo Mesmo. O mesmo e o Outro não se confundem: Eu ainda sou Eu, o Outro ainda é o Outro. A coisificação do Outro é a sua morte, e é também a morte do Mesmo, já que o Eu só é pelo chamado do Outro. É a segurança desumanizante da Totalidade. É no princípio da separação, da não coisificação do Outro (e do Mesmo), que Levinas (1989, p. 66) sustenta sua ideia de Infinito:

Para ter a ideia do Infinito, é preciso existir como separado. Esta separação não pode produzir-se como fazendo eco à transcendência do Infinito. Senão, a separação manter-se-ia numa correlação que restauraria a totalidade e tornaria ilusória a transcendência. Ora, a ideia do Infinito é a própria transcendência, o transbordamento de uma ideia adequada. Se a totalidade não pode constituir-se é porque o Infinito não se deixa integrar.

A relação com o Outro é infinição. Da mesma forma que o Mesmo não coisifica e objetifica o Outro, o Outro não coisifica o Mesmo. Não há uma conceituação possivel do que é a "infinição", como experiência transcendental com o absolutamente Outro ela escapa ao enquadramento conceitual. Da mesma forma também não é possivel conceituar o "encontro", a não ser pela negativa: não é um contato, não é uma absorção, não é uma relação instrumental etc. Assim também é o Outro, que escapa da possibilidade de conceitualização e se apresenta sempre faca a face, como rosto, cuja violência do encontro chama o Eu à responsabilidade ética, gratuita e inalienável (LEVINAS, 2012, p. 50; 2014, p. 28).

É a resposta ao chamado do Outro, pelo rosto que se manifesta e transcende, na relação ética da responsabilidade, que estão fundadas as con- dições para a justiça, para um verdadeiro "estado de exceção". O rosto diz: "tenho fome" e "não me mate"; a resposta é o fundamento da justiça. Conforme Souza (2001, p. 272, grifo do autor),

\begin{abstract}
A justiça se propõe assim, para Levinas, não como uma dimensão de realidade a ser simplesmente teorizada desde a facticidade mesma da realidade, mas, antes, como uma condição fundamental para que a realidade possa ser considerada propriamente real. A justiça, ou seja, a ética realizada e em realização, é a estrutura basilar do sentido humano e cosmológico, sem a qual a realidade não é, a rigor, segundo esta linha de pensamento, nem ao menos pensável. Ajustiça, portanto, não é por este autor concebida como uma questão teorética, nem ao menos como uma questão existencial, mas como uma questão, poderiamos dizer, fundacional, sem a qual as restantes determinações do mundo e da realidade não podem ser propriamente concebidas enquanto questões radicalmente humanas, pelo menos não em sua plenitude.
\end{abstract}

No "estado de exceção" da violência sem memória, a responsabilidade, é subvertida pelo esquecimento, pela indiferença com o Outro e pela naturalização das relações instrumentais, caracteristicas de um criativo processo educacional que se recusa a uma pedagogia do tempo, que não considera a temporalidade e normaliza o presente como algo imutável, ou cujas mudanças estão além do que fazemos. A justiça é subvertida em meras questões associadas ao Direito, e normatizada.

Nessa senda, estamos convencidos de que há uma conexão entre a ética da alteridade e da responsabilidade e uma estética do encontro, ou melhor, do desejo pelo encontro. Uma estética que não violenta o Outro tomando seu rosto por uma imagem que é "lida" pelo Mesmo e incorporada à mesmidade. Uma estética que assume que o rosto escapa à representação, assim como o sofrimento do Outro é irrepresentável. Uma estética que não tem no Outro seu objeto. A ideia de estética que defendemos aqui segue a trilha de Adorno (1982, p. 15), quando afirma que a identidade estética é a oposição à compulsão que anula o não idêntico, subsumindo o Outro um mero objeto de conhecimento e, assim, não encara todas as complexidades da realidade. Embora seja originária do Eu, enquanto a relação ética tem origem no chamado do Outro, a relação estética manifesta um desejo desse chamado: 
assim, é erótica, no sentido atribuido por Gur-Ze'ev. Estamos convencidos de que é no Eros contraeducativo da Filosofia Diaspórica de Gur-Ze'ev que encontramos as possibilidades de uma estética que não corrompe a ética da alteridade em mais do Mesmo, assim como corajosamente encara de frente o real concreto, a memória.

\section{O verdadeiro estado de exceção da estética antropológica: o Eros contraeducativo}

O projeto da contraeducação de Gur-Ze'ev (2010b, p. 43) manifesta um entendimento de educação que resiste à normalização da racionalidade instrumental, e é portanto uma educação contra a educação normalizante, e pode ser definida como "[...] aberta e não controlada, responsável e liberal para com a diferença do Outro, dando nascimento a uma constituição que abraça o desconhecido e a autossuperação". Já a Diáspora não significa um movimento físico, mas uma abertura para o Outro, pois quem está em Diáspora está constantemente em contato com a outridade (GUR-ZA'EV, 2005a, p. 164). Para Gur-Ze-ev (2010a, p. 340), Diáspora é um conceito filosófico muito próximo a um imperativo existencial, uma condição humana, que precisa ser compreendida hodiernamente em face da dificuldade de manifestações de existência livre, diante do desequilibrio ecológico produzido por ideologias normalizadoras em sua criatividade, assim como diante "do rápido desaparecimento das pré-condições para a confiança ou até mesmo da esperança de epistemologias objetivo-fundacionalistas". Diáspora é, portanto, encarar o abismo do "estado de exceção" de frente e assumir os desafios da responsabilidade pelo mundo e pela diferença, pela outridade do Outro e do Eu. É experienciar a crise, "a possibilidade de salvar o propósito da luta pela autoconstituição de um indivíduo livre, solidário, diaspórico; uma luta pelo esclarecimento de causas morais via envolvimento social, via práxis política" (2005b, p. 188). Viver em condição diaspórica significa assumir uma atitude crítica para consigo, com Outros, e a realidade, encorajando que outros façam o mesmo; crítica aqui significa meramente estabelecer a validade de posições e argumentos (GUILHERME, 2019).

Assim sendo, se não é possivel enquadrar o Outro em critérios cognosciveis e controlados, o encontro pode reservar surpresas, não raro desagradáveis e que provocam uma crise de sentidos em todos os que dele participam. O encontro é o próprio inesperado, inseguro, incerto. O encontro com o Outro, que respeita e deseja a outridade como riqueza, não pode ser programado. É estar preparado para o encontro ético, improvisado e não normalizante com a diferença e com o inesperado, o caráter da responsabilidade exigido pela postura diaspórica e contraeducativa no mundo (GUR-ZE'EV, 2010a, p. 344). Não é negligente, não é indiferente e não abandona o Outro. Em uma dimensão retrospectiva, se esforça para evitar o esquecimento de seus sofrimentos e de suas alegrias. Mesmo o sofrimento, nessa abordagem, é um sofrimento digno já que não subsume o Outro que foi impedido de manifestar seu Ser no mundo em um número, um membro da espécie. Assim, em Gur-Ze'ev (2005b, p. 191192), a espera esperançosa e corajosa disposta à abertura para o desconhecido, o absolutamente Outro, exigida pela improvisação responsável da postura contraeducativa implica vigilância de uma ação que resiste à injustiça, à violência, ao abandono, enfim, ao mal banal e naturalizado e, assim, na própria incerteza de resultados (o caráter da responsabilidade, mergulhado na incerteza), oferece as condições para o encontro ético, para "a realização da singularidade do nascimento [Gênesis] a cada novo momento" (2005b, p. 191-192). É uma forma estética em que dá testemunho do Outro, que o dignifica e dignifica o Eu: o fenômeno ético da separação (Levinas).

Em Gur-Ze'ev, é o Eros o amor específico advogado pela contraeducação. À primeira vista, essa pode parecer uma noção estranha, quer dizer, unir Eros e educação. Entretanto, o filósofo extrai a ideia de Eros de Platão, em Fedro e em O Banquete. Em O Banquete, Platão (2001, p. 27), ${ }^{4}$ pela boca de Sócrates, afirma que o amor é uma forma de carência. Desejo o que não tenho,

4 Disponivel em: http://wwww.dominiopublico.gov.br/download/texto/cvo00048.pdf. Acesso em: 6 jun. 2020 
por isso amo. Em diálogo travado com Agatão, Sócrates indaga: "Não é isso então amar o que ainda não está à mão nem se tem, o querer que, para o futuro, seja isso que se tem conservado consigo e presente?" E, ao receber a afirmativa do interlocutor, indaga novamente, "Esse então, como qualquer outro que deseja, deseja o que não está a mão nem consigo, o que não tem, o que não é ele próprio e o de que é carente; tais são mais ou menos as coisas de que há desejo e amor, não é?". Em Fedro (PLATÃO, 2005, p. 69), novamente pela boca de Sócrates, "É evidente que o amor é desejo". A relação do Eros como manifestação estética a partir da ética da responsabilidade se dá na relação com a outridade do Outro, com a impossibilidade de possuir o Outro como uma coisa. Não é possivel possuir o Outro como a um objeto e, nem mesmo, ter a completa compreensão do Outro e da sua outridade. Por isso o desejo, por isso o quero, por isso o amo.

Conforme Luzon (2016), a ideia de Eros em Gur-Ze'ev significa uma forma de excitação cognitiva que se manifesta intensamente quando da tomada de consciência da existência do Outro. Luzon (2016, p. 467) ainda sustenta que há no hebraico, língua materna de Gur-Ze'ev, um conceito similar em significado e, mesmo, na pronúncia: Erouth. Erouth implica um estado de espirito, uma disposição, que se manifesta no despertar plenamente consciente da existência do que é exterior, separado do Mesmo, portanto, "infinito" em termos de Levinas. A relação entre Eros e Erouth conduz, na leitura que faz Luzon da obra de Gur-Ze'ev, a outro termo do hebraico, O'rerouth, que tem relação com a sensualidade, com o amor do qual Adorno denuncia nossa carência: o desejo libidinal por outras pessoas. Importante que tanto Erouth quanto O'rerouth estão subsumidos na noção de Eros da contraeducação, ou melhor, na noção mesmo de contraeducação erótica que só é possivel pela tomada de consciência do Outro, pelo desejo do Outro. Conforme Luzon (2016, p. 467),

sem a excitação cognitiva em relação ao Outro, a excitação sensual não poderia existir - uma pessoa não é atraída eroticamente, sensualmente e afetivamente, em direção a si mesmo. Isso não significa que alguém não possa amar a si mesmo ou ser despertado pela própria aparência. Significa apenas que, para ser afetivamente suscitado de uma maneira que expresse o desejo de estar unido ao Outro, deve-se primeiro estar num estado de excitação cognitiva em que se encare aquele Outro como diferente de si mesmo.

A excitação cognitiva é também uma experiência estética - ela envolve não apenas nossas mentes, mas nossos corpos; o aprender, a educação, tem um importante componente de corporalidade, de experiência, de vivenciar que não pode ser esquecido ou presumido como algo não significante. A experiência estética envolve o desejo pelo encontro, aquilo que não se pode possuir. Se o Eros implica despertar para a existência do Outro pelo desejo, ele também representa um amor que desperta para o desejo de educar. No Fedro (PLATÃO, 2005, p. 69-75), no "primeiro discurso de Sócrates", esse despertar emerge como a entrega de si mesmo para o que é belo, para o Outro, para o novo. Essa é a própria noção de Eros que oferece a possibilidade de, e é possibilizada por, uma Ética da responsabilidade - o que é muito consonante com Levinas. A responsabilidade do Eros contraeducativo é manifesta por Gur-Ze'ev (2005a, p. 343):

\begin{abstract}
enquanto chamando pela criatividade, pelo amor pela vida e pela responsabilidade do eterno improvisador, ela também está comprometida em rejeitar todos os dogmas e outras formas de fechamento e mesmice, e também recusa todas as versões do niilismo e do relativismo.
\end{abstract}

\section{Considerações finais}

Neste artigo, primeiramente discutimos o "estado de exceção" da violência sem memória e reafirmamos o dever de memória que se opõe à barbárie enquanto nos referimos a Adorno. Na segunda parte, analisamos criticamente a ética da responsabilidade apresentada por Levinas. Na última parte, apresentamos o conceito da estética do Eros contraeducativo que nos foi fornecido por Gur-Ze'ev.

Fica claro que a postura de um pensar histórico ético e estético perpassa a recusa de esquecer e o desenvolvimento de uma atitude crítica para consigo mesmo, para com o Outro, e finalmente 
para com a realidade. Esse modo de pensar é ético porque existe fundamentalmente em razão da responsabilidade para com Outro, e é estético porque se manifesta no desejo do encontro com o Outro. Esse pensar é também histórico porque nos oferece as possibilidades de criação de um verdadeiro "estado de exceção", não mais esse em que vivemos onde a barbárie foi normalizada, mas o de uma vida que se recusa a ser vivida sem amor.

\section{Referências}

ADORNO, T. Educação e emancipação. Trad. de W. L. Maar. Rio de Janeiro: Paz e Terra, 1995.

ADORNO, T. Teoria estética. São Paulo: Martins Fontes, 1982, p. 15 .

ADORNO, T.; HORKHEIMER, M. Dialética do Esclarecimento. Trad. de G. A. de Almeida. Rio de Janeiro: Zahar, 1985.

AGAMBEN, G. Homo Sacer: o poder soberano e a vida nua I. Trad. de H. Burigo. Belo Horizonte: Editora UFMG, 2002.

AGAMBEN, G. O que é o contemporâneo? E outros ensaios. Trad. de V. Nicastro Honesko. Chapecó-SC: Argos, 2009.

ARENDT, H. De la historia a la acción. Trad. de F. Birulés. Barcelona; Buenos Aires; Cidade do México: Ediciones Paidós, 1995.

BENJAMIN, W. Escritos sobre mito e linguagem: (19151921). Trad. de S. K. Lages e E. Chaves. São Paulo: Editora 34, 2011.

BENJAMIN, W. Magia e técnica, arte e politica: ensaios sobre literatura e História da cultura. Trad. Sérgio Paulo Rouanet. $7^{\mathrm{a}}$ ed. São Paulo: Brasiliense, 1994.

BORGES, J. L. Funes. Obras completas: 1923-1972. Buenos Aires: Emecé Editores, 1974.

BRECHT, B. Teatro completo. Trad. R. Schwarz. Rio de Janeiro: Paz e Terra: 1990. v. 4.

GUILHERME, A. A. Michel Serres' Le Parasite and Martin Buber's I and Thou: Noise in Informal Education Affeting Dialogue Between Communities in Conflict in Midle East. Educational Philosophy and Theory, Randwick. Australia, AU, v. 47, n. 10, p. 1052-1068, 2015. https:// doi.org/10.4324/9781315113296-5.

GUILHERME, A.; MORGAN, W. J. Filosofia, Diálogo e Educação: nove Filósofos Europeus Modernos. Brasilia: UNESCO, 2019.

GUILHERME, A. Gur-Ze'ev and Education: Pedagogies of Transformation and Peace. London e New York: Routledge. 2019. https://doi.org/10.4324/9781315659145.

GUR-ZE'EV, I. Adorno and Horkheimer: Diasporic Philosophy, Negative Theology, and Counter education. Educational theory, Illinois, v. 55, n. 3, p. 343-365, 2005 a. https://doi.org/10.1111/j.1741-5446.2005.00007.x.
GUR-ZE'EV, I. Beyond postmodern feminist Critical Pedagogy: Toward a Diasporic philosophy of conter-education. In: GUR-ZE'EV, I. (org.). Critical theory and critical pedagogy today: toward a new critical language in education. Haifa: Universidade de Haifa, 2005b. p. 149-183. https://doi.org/10.1163/9789087903329_009.

GUR-ZE'EV, I. Diaporic Philosophy, Counter-Education and Improvisation. Policy Futures in Education, [s. l.], v. 8, n. 3-4, p. 340-345, 2010a. https://doi.org/10.2304/pfie.2010.8.3.340.

GUR-ZE'EV, I. Diasporic Philosophy, Counter-Education and Improvisation, Studies in Philosophy and Education, Dordrecht, n. 28, p. 386-381, 2007. https://doi. org/10.1007/s11217-007-9081-Z.

GUR-ZE'EV, I. É possivel uma educação crítica no ciberespaço? Comunicações, v. 9, n. 1, 72-98, jun. 2002. https:// doi.org/10.15600/2238-121X/comunicacoes.vgn1p72-98.

GUR-ZE'EV, I. The Nomadic existence of the eternal improviser and diasporic co-poiesis today. In: GUR-ZE'EV, I. (org.). Diasporic Philosophy and Counter Education. Rotterdan: Sense Publishers, 2010b. p. 29-46. https:// doi.org/10.1007/978-94-6091-364-8_1.

GUR-ZE'EV, I. The Nomadic existence of the eternal improviser and diasporic co-poiesis today. In: GUR-ZE'EV, I. The possibility/impossibility of a new critical language in education. Rotterdan: Sense Publishers, 2010c. p. 29-44. https://doi.org/10.1007/978-94-6091-364-8_1.

JASPERS, K. A questão da culpa: a Alemanha e o Nazismo. Trad. De C. Dornbush. São Paulo: Todavia, 2018.

KOSELLECK, R. Futuro Passado. Trad. de W. P. Maas e C. A. Pereira. Rio de Janeiro: Contraponto; Ed. PUC-Rio, 2006.

KYONG-MIN, Son. Walter Benjamin's Politics of Experience. Constellations, Oxford, v. 20, n. 4. p. 615-629, 2013. https://doi.org/10.1111/1467-8675.12061.

LÉVINAS, E. Autrement qu'être ou Au-delà de l'Essence. Paris: Martinus Nijhoff, 1978.

LEVINAS, E. Entre nós: ensaios sobre a alteridade. Trad. de P. Pivatto. Petrópolis, RJ: Vozes, 1997.

LEVINAS, E. Ethics and Infinity. Pittsburgh, PA: Duquesne University Press, 2009.

LÉVINAS, E. Humanismo do Outro homem. 4. ed. Tradução de Pergentino S. Pivatto (coord.). Petrópolis, RJ: Vozes, 2012.

LEVINAS, E. Totalidade e infinito. Tradução de José Pinto Ribeiro. Lisboa, Portugal: Edições 70, 1989.

LÉVINAS, E. Violência do rosto. Trad. F. S. Moreira. São Paulo: Loyola, 2014.

LUZON, P. The Eros of Couter Education. Journal of Philosophy of Education, London, v. 50, n. 3. p. 461-473, 2016. https://doi.org/10.1111/1467-9752.12147.

PIVATTO, P. S. Responsabilidade e justiça em Levinas. Veritas, Porto Alegre, v. 46, n. 2, p. 217-230, 2011. https:// doi.org/10.15448/1984-6746.2001.2.35005.

PLATÃO. Fedro. Trad. de A. Marins. São Paulo: Martin Claret, 2005.

PLATÃO. O banquete: o amor, o belo. Trad. desconhecido. Domínio Público, s/d. 
SANTAELLA, L. Comunicação ubiqua: repercussões na cultura e na educação. São Paulo: Paulus. 2013.

SERRES, M. Le Parasite. Paris: Grasset. 1980.

SERRES, M. The parasite. Minneapolis, MN: Minneapolis University Press, 2007.

SOUZA, R. T. de. Adorno \& Kafka: paradoxos do singular. Passo Fundo: IFIBE, 2010.

SOUZA, R. T. de. Por uma estética antropológica desde a ética da alteridade: do "estado de exceção" da violência sem memória ao "estado de exceção" da excepcionalidade do concreto. Veritas, Porto Alegre, v. 51, n. 1, p. 129-139, 2006. https://doi.org/10.15448/1984-6746.2006.2.1852.

SOUZA, R. T. de. Razões plurais: itinerários da racionalidade ética no século XX - Adorno, Bergson, Derrida, Levinas, Rosenzweig. Porto Alegre: EDIPUCRS, 2004.

SOUZA, R. T. de. Rosenzweig entre a História e o Tempo: Prefácio. In: ROSENZWEIG, F. Hegel e o Estado. Trad. de Ricardo Timm de Souza. São Paulo: Perspectiva, 2008a.

SOUZA, R. T. de. Sobre a construção do sentido: o pensar e o agir entre a vida e a filosofia. $2^{a}$ reimp da $1^{a}$ ed de 2003. São Paulo: Perspectiva, 2008b.

SOUZA, Ricardo Timm de. Justiça, liberdade e alteridade ética. Sobre a questão da radicalidade da justiça desde o pensamento de E. Levinas. Veritas, Porto Alegre, v. 46, n. 2, p. 265-274, 2001. https://doi. org/10.15448/1984-6746.2001.2.35008.

\section{Bruno Antonio Picoli}

Doutor em Educação pela Pontificia Universidade Católica do Rio Grande do Sul (PUCRS) em Porto Alegre, RS, Brasil. Professor na Universidade Federal da Fronteira Sul (UFFS) em Chapecó, SC, Brasil.

\section{Alexandre Anselmo Guilherme}

Doutor em Filosofia pela Durham University, Inglaterra. Professor na Pontifícia Universidade Católica do Rio Grande do Sul (PUCRS) em Porto Alegre, RS, Brasil.

\section{Endereço para correspondência}

Alexandre Anselmo Guilherme

Pontificia Universidade Católica do Rio Grande do Sul

Programa de Pós-Graduação em Filosofia

Av. Ipiranga, 6681, Prédio 8, $4^{\circ}$ andar, Sala 403

Partenon, 90619900

Porto Alegre, RS, Brasil. 